\title{
Professor Ken Parry Biography
}

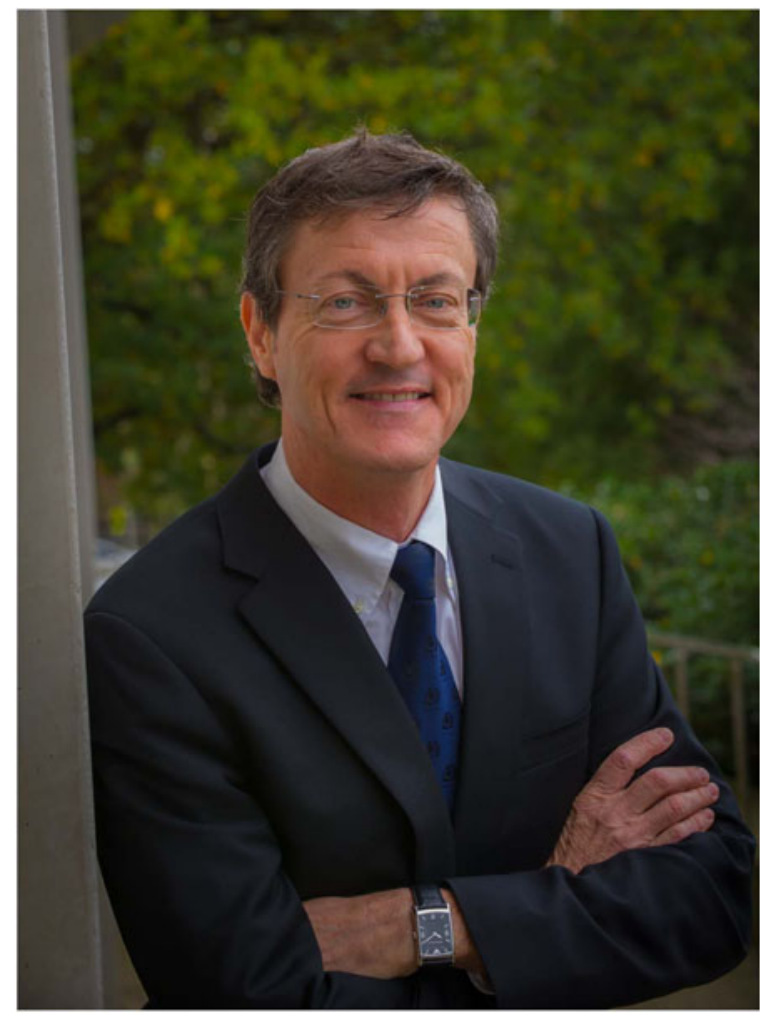

Ken Parry, FAIM, FAHRI, FLTF, FANZAM, was a Professor of Leadership Studies and co-Director of the Deakin Leadership Centre at Deakin University. Prior to that he held professorial positions at Bond University and Griffith University, and was the Founding Director of the Centre for the Study of Leadership at the Victoria University of Wellington, New Zealand. He has researched, studied and consulted in Australia, New Zealand, the USA, Europe and South-East Asia. Ken wrote or edited eight books and over 40 journal articles, mainly on the topic of leadership. His best-selling book, A Very Short, Fairly Interesting and Reasonably Cheap Book about Studying Leadership, co-authored with Brad Jackson, was published in three editions and in four languages. In 2016, Ken received The Leadership Quarterly Decennial Award for the most influential article over the last 10 years. Ken was Founding Editor of the Journal of Management \& Organization, the research journal of the Australian and New Zealand Academy of Management. As doctoral supervisor, Ken had 17 successful completions. Prior to joining academia Ken had nine years of experience in the manufacturing industry as an inventory manager for Meyers-Taylor in his home town of Brisbane. A highly accomplished speaker, Ken notably addressed the Senior Executive Service of the Australian Public Service at the National Press Club. Ken passed away on February 11, 2018.

A full obituary for Ken Parry appeared in the Journal of Management \& Organization (2018), 24:3, pp. 329-331. 


\title{
'Take Your Lead': In Search of Very Short, Fairly Interesting, and Reasonably Impactful Contributions to the Future of Leadership Studies
}

\author{
Brad Jackson ${ }^{1 \star}$, Steve Kempster ${ }^{2}$ and Liz Fulop ${ }^{3}$ \\ ${ }^{1}$ Griffith University, Nathan, QLD 4111, Australia, ${ }^{2}$ Lancaster University Management School, Lancaster, UK and ${ }^{3}$ Griffith \\ University, Gold Coast, QLD 4222 \\ ${ }^{\star}$ Corresponding author. Email: b.jackson@griffith.edu.au
}

\begin{abstract}
This Special Issue has been created in dedication to the life and career of Professor Ken Parry, the founding editor of the Journal of Management \& Organization. Ken maintained an impressively wide array of research interests, but two primary concerns consistently stood out. First, he was concerned with the loss of virtue practices in organisational life which has led to ever-decreasing attention being paid to societal values and the social responsibility of leadership practice and leadership scholarship. Second, and related to this concern, Ken was committed to pushing back against the 'manufacturing' world of journal article production as the consequence of the imperceptible growth of the neo-liberal norms of university life. Drawing on Ken Parry's example, the editors of this Special Issue have invited leadership and management scholars to take Ken's lead by actively questioning assumptions that many of us take-for-granted; to speak up, and loud, against the 'scientism' that dominates the management field, pushing for plausibility, relevance and impact in our work; to pursue quality research through a multiplicity of methods, however unconventional they might be; and to place a high premium on teaching and student supervision. The 12 short and long articles that are featured in the Special Issue respond to Ken Parry's call by taking their own lead and speaking individually and compellingly to one or more of these critical challenges.
\end{abstract}

Key words: Ken Parry; leadership education; leadership research; responsible leadership

\section{'Take Your Lead'}

Too often our eyes are drawn to the minutiae of our research endeavours; too frequently we restrict our research questions so that they become minor and obtuse. We so infrequently raise our eyes to consider and explore the big challenges of our time. Professor Ken Parry was a rare colleague whom we collectively celebrate for 'taking his lead' in seeking: to question assumptions that many of us take for granted; to speak up, and loud, against the 'scientism' that dominates the management field and to push for plausibility, relevance and impact; to pursue quality research through a multiplicity of methods however unconventional; and to place a high premium on teaching and student supervision.

We shall explore each of these elements as the focus of this introduction to this Special Issue (SI). In relation to the last aspect of Ken's leadership, the SI gives prominence and voice to many of Ken's past $\mathrm{PhD}$ students to speak on issues and concerns that matter deeply to them. We have also invited a range of international colleagues who Ken knew well and whom Ken valued for their challenging opinions within the field of leadership studies. Ken's contributions to the leadership field through more than 40 journal articles, seven books, numerous chapters, conference papers and prominent keynotes are well known and of great significance.

Perhaps most well- known is the 'Very Short ...' book. In the last edition, Ken (co-writing with Brad) penned many of his concluding thoughts on the state of leadership research, some of which we shall unpack below (Jackson \& Parry, 2018). The final proofs of the third edition of the book 
were concluded in the final days of Ken's life. In the original version of the book, the title of the final chapter was 'Take Your Lead' (Jackson \& Parry, 2008). In many ways this was and is a 'call to arms' as Ken might have said which is intended for leadership scholars and for leadership practitioners to fully realise their purpose and their contributions. Alternatively framed, 'Take Your Lead' speaks to two of Ken's primary concerns throughout his career: first, after MacIntyre (1985), he was concerned with the loss of virtue practices in organisational life which has led to ever-decreasing attention being paid to societal values and the social responsibility of leadership practice and leadership scholarship. Second, and related to this concern, Ken was committed to pushing back against the 'manufacturing' world of journal article production as the consequence of the imperceptible growth of the neo-liberal norms of university life. In short, and drawing on The Who (whom Ken would invariably cite) he inspired us with the familiar clarion call but one not normally associated in academe - 'We won't get fooled again!' - a theme that is also explored in one of the SI's papers.

In the last few years of his life Ken became impassioned about the grand challenges facing humanity as captured in his last book, Good Dividends: Responsible Leadership of Business Purpose (Kempster, Maak, \& Parry, 2019). The responsibilities of leadership to connect business value with social impact are not presently the everyday concerns of those who lead. Too often the external goods (profits, salaries, bonuses, cars, privilege and entitlement) dominate the values of those who lead. Similarly, external goods have begun to dominate the increasing predominance of neo-liberal practices in universities throughout the world. The main reason why most scholars, entered academia was not to do our bit to contribute to the productivity imperative that has come to dominate our world, most notably through the ceaseless demand for more and higher ranked publications. Most of us signed up primarily to enhance and enrich society through the impact of our research and our teaching. The leadership field has notably under-achieved with regard to impact despite the enormous investment in the multi-billion dollar industry that supports it. Thus far, the leadership field has in all frankness a highly impoverished return on investment. These were primary concerns for Ken, often expressed over German beers, at conferences, with Deans and Vice-Chancellors and with many hundreds of managers. For example, we recall a conference paper Ken gave at the ILA Oceania conference that was held at the University of Auckland Business School in 2013. He was sandwiched between two earnest $\mathrm{PhD}$ students keen to unleash their data on the audience. Ken's argument, without notes and with wry humour in abundance, was on the purpose of leadership development: 'All we do [in leadership development] is provide a bit of $\mathrm{R} \& \mathrm{R}$, patch them up and send them back to the front line'. He turned the lens on to us, researchers and developers, to unsettle the audience to question our motivations and complicity in 'taking the [King's] shilling'. This was but one example of the encouragement that Ken gave to others to take their lead in stimulating change and not accepting the status quo.

Encouraging others to 'take their lead' with their research assumptions and methods were central to Ken's legacy. For example, he was renowned in the leadership field for bringing grounded theory to provide novel understandings of leadership (Parry, 1998). Indeed, through the use of grounded theory his work was perhaps the first, certainly it was the most robust, to argue that the ontological preoccupation with leadership as an individual person placed in a position of authority was misplaced. Instead he argued leadership should be viewed primarily as a process of social influence. Such an ontological reframing of leadership not only questioned the underlying assumptions of the phenomenon, but opened up a rich stream of research to understand such processes. For example, he argued that substantial insights into leadership could be yielded by foregrounding the role of leadership as a narrative (Parry \& Hansen, 2007).

By positioning leadership as a process Ken gave emphasis to the practices and the activities of leading. But it also gave attention to context. Too much leadership theory has been developed acontextually. By way of correction, Ken highlighted the imperative of grounding leadership theory in the nuances and complexities of context. His disquiet with scientism and the dominant 
hold it had on leadership theorising and research, became manifest in his own ontological and methodological plurality. He challenged the field, and indeed his own work (in Kempster and Parry, 2011) by drawing on a critical realist frame. He also explored the opportunities for using autoethnography in leadership (Boyle and Parry, 2007). But he was not constrained from considering whether one person's experience of a phenomenon could be compared to others. He explored the possibility of combining post-positivist and positive techniques by applying the autoethnographic method to data presented by Shamir and Kark (2004) to understand the role of 'love' in the leadership relationship (Parry and Kempster, 2014). In doing this, he sought to go beyond one voice to examine how the resonance of a manager's experience of emotional labour within leadership could be measured against other managers' experiences (Kempster \& Parry, 2018a).

Ken's pluralistic bricolage of approaches is a very big lesson for us all. He was at ease connecting the great divide that exists between nomothetic methods and ideographic methods. What was paramount was the plausibility, the relevance and the impact of the research. Perhaps too often we become entrenched in our traditions and camps, limiting our ability, on the one hand, to connect our work to the complexities of context and a manager's practice; and, on the other hand, to engage in robust theory development that can reach beyond experience and specific contexts to provide explanations of phenomena that remain plausible, relevant and impactful to other contexts.

And yet there is more. Have we already mentioned Ken's great dislike of the word 'leader' (Kempster \& Parry, 2018b)? This is a wonderful irony that perhaps quintessentially captures the essence of the man. Someone who has greatly shaped the field of leadership research and thousands of students studying leadership to enhance their ability to lead, fundamentally railed against what most would consider as being the core element of the construct that is leadership:

I am on the Editorial Board of The Leadership Quarterly journal; although that might be in doubt after this book comes out. I have reminded authors and editorial colleagues many, many times that this is a Leadership journal, and not a Leader journal. Subtle threats have been made about being removed from the Editorial Board. Perhaps my windows will get smashed. Perhaps I will be put on an agrarian steam train and taken somewhere. I should be so lucky (2018: 66).

The wry humour expressed here was so very typical of Ken. Although he had much to say and contribute he never took himself too seriously. What he did take most seriously was the time and attention to his students. In the current academic world, which has become dominated by the research productivity regime and heavily skewed towards publications as the route for advancement, teaching and supervision is often the first casualty. This was a priority for Ken - a vocational commitment in which teaching and research were two sides of the same coin. How many of us give such a priority to teaching and use the context of teaching to develop and apply research to understand relevance and impact? The enthusiasm from Ken's past PhD students to participate in this SI is testimony to the legacy that teaching and supervision can generate.

In being charged with the honour of co-editing this SI in dedication to Professor Ken Parry, we selected the following key tenets associated with Ken's life's work to provide guidance to the contributors to the SI:

- Arguments framed by the 'Take Your Lead' notion

- Concisely written - Ken had a passion for short and clear sentences.

- Strong relevance to leadership theory, practice and policy - more than a bolt-on at the end explicit and implicit as a red thread that runs through the paper. 
- Research that goes beyond data. Ken was impassioned about the need for researchers to appreciate the nature of the data being explored (i.e., the reliability, relevance, validity and plausibility). Findings do not stand alone but connect to practice and policy.

- Findings are interpreted within context - hence the concern for relevance, validity and plausibility.

- If concerns for reliability, relevance, validity and plausibility are met then unconventionality will also be encouraged and nurtured.

- The 'That's interesting' test speaks to novelty, challenge and connection of theory and practice.

To contribute to the SI we invited a number of colleagues with whom Ken worked closely throughout his career, including colleagues with whom he was still researching, and some of his past doctoral students. We recognise that the authors who have contributed to this SI are only a small fraction of the colleagues whom Ken worked with throughout his illustrious career and we apologise for those whom we did not approach and would have relished the opportunity to contribute. To you we say please take advantage of other forums through which to acknowledge Ken's contribution. To allow for the widest variety of voices and in keeping with the 'Very Short' motif, we requested short pieces (typically around 1,500 words) that could provide a compellingly singular argument that would engender an immediate and memorable response in readers. In addition, we invited four longer articles that could tackle more complex leadership problems that Ken was drawn to throughout his career. We did not want each paper to be a testimonial to him. He would not have wished for this. Ken would want the arguments; he would want colleagues to 'Take Their Lead'. We have, however, also asked each of the contributors to provide a brief reflective comment about their connection to Ken and his work. What follows is the customary brief outline of the dozen papers that we are proud to feature in this SI, beginning with the eight short articles and then following on with the four long articles.

The short papers section opens with Dennis Tourish, the Editor of Leadership. Building on Ken's concerns with respect to the field of leadership studies being distracted from the grand challenges facing humanity, Dennis pulls no punches in articulating the need for the leadership field to 'aim higher and do better'. He lays out the rich opportunity for the leadership field to engage and move into the space inhabited by grand challenges. In this way he encourages the leadership field to move away from its preoccupation with meaningless theories and the endless analysis of the same things through the bias for positive correlations, and revisit why we originally became academics to rekindle 'a curiosity about ideas, a love of writing and the desire to make a positive difference to the world in which we live'.

Next, Michael Muchiri, of whom Ken was an important mentor, along with Remi Ayoko and Sherish Shahid, examine Ken's seminal work on the social process of leadership. They note that this body of work provoked a significant shift in the understanding of the processes of influence in the context of achieving adaptation and change in response to changes in an organisation's environment. Reflecting on the state of leadership literature in recent years, they answer Ken's challenge to broaden our understanding of the positive outcomes that can be achieved by the social processes of leadership and propose a research framework that inter-links the social processes of leadership with psychological capital.

In the third short article, Sarah Proctor-Thompson, one of Ken's former doctoral students, wonderfully captures the essence of Ken's work as a dialogic humanist who was imbued with a highly contextualised orientation to leadership. She compellingly argues that values need to come to the fore in the leadership practice that is associated with the roles and responsibilities of those who lead thus, closely aligning with Ken's passion for virtue and virtuous organisations. Sarah speaks to the need for leadership theory to deeply embrace relationships and contexts, arguing that too often leadership theory severs 'individual leaders from their relationships, their organisational contexts and the broader environment' (p. https://doi.org/10.1017/jmo.2019.18). Sarah evocatively 
concludes with hope and expectation that leadership research and practice will re-vitalise itself to meet the needs of humanity - a continual reframe that emerges from so many of the contributors to this SI.

Jon Billsberry, John Molineux and Claudia Escobar, three of Ken's colleagues from Deakin University, pursue another line of inquiry that Ken was also closely connected with, that of leadership development. Jon and his colleagues take us back to the roots of leadership learning and the most formative learning contexts in our understanding of leadership - that of childhood. They argue that too often leadership development is a lost cause - the mental furniture in managers' heads is fixed and we are merely tinkering - echoing Ken's notion of leadership development as R\&R before they return to the front line. Billsbery et al. lay out an alternative context and process for leadership development - the class room. We know very little of this important stage in leadership knowledge construction, such as the nature of implicit leadership theories through various stages of childhood. What we do know is that this formative stage is where character, virtue and an enduring sense of purpose can be shaped and encouraged for the leadership challenges that lay ahead.

Another of Ken's former doctoral students, Melanie Kan, explores the relationship between leadership and legacy, something that is generally recognised as being salient but rarely analysed from an academic perspective. Drawing from her own sense-making of Ken's legacy, Melanie critiques the dearth of attention from the leadership field given to legacy. She does not restrict her attention merely to leaders, inviting us to consider broader notions of leadership embracing followers as part of the legacy of leadership. If we consider the potential legacy of leadership research to enhance those in powerful positions of disproportionate influence to embrace notions of legacy associated with virtuousness and thriving communities, then our field will have left a great legacy to humanity.

A third former doctoral student with whom Ken also published, Nezar Faris, examines the complex context that influences and impacts upon Muslim leadership in Australia. For Muslims, leadership is a deeply contested notion, which is most difficult to unravel and advance. Drawing on Ken's approach to studying leadership, Nezar argues that future research on Australian Islamic leadership needs to draw on a wider range of methods and paradigms. For example, there is a need to explore the relational dynamics of Australian Muslim leaders with the Muslim communities in general and young Muslims in particular. He notes with sorrow tinged with hope that perhaps a worthy starting point would be to research what Australian and New Zealand Muslim leadership can learn from the tragic Mosque shootings that took place on March 15, 2019 in Christchurch, most especially how both Islamic and non-Islamic communities will galavanise and rebuild their lives and their relationships through different acts of leadership. Islamic leadership needs to be better understood and should not remain a marginalised area because never has so much depended on it.

Jonathan Gosling provides the penultimate short paper, focusing on the pleasures and power of 'Taking Your Lead'. In his typically sparkling manner, Jonathan captures the essence of the joys and the struggles of formally leading in a university context, something which Ken quite wisely avoided throughout his career. Drawing from ethnographic and autoethnographic insights he neatly, and succinctly, captures the pleasures that can be derived from the powers of holding leadership office in a three-fold typology: identity related pleasures in finding and crafting an identity associated with efficacy, status and a sense of self-mastery; influence-oriented pleasures such as making a difference, steering and supporting priorities; and interactive pleasures, including being in relationship with others, and thus being part of something more than oneself. As three former academic leaders, we have trouble recalling the pleasures of holding office but this article has certainly given us something to think about.

The final short paper is provided by Keith Grint, the Founding Co-Editor of Leadership. The paper resonates strongly with Ken's orientation to the social construction of leadership. Keith cleverly re-conceptualises the historic phenomenon of mutiny as an act of leadership to offer 
us a timely and critical reflection on our contemporary concerns with truth and fake news. Two cases of mutiny in the UK Navy are described. At face value both are very similar. Yet Keith invites us to understand the power of interpretation of facts and thus the different interpretations that can be constructed. What is interesting here is not the dispute between truth and fake news, but which account is believed by whom, and why, and what the consequences are for those involved. He leaves us with a cautionary reminder that, if academics are to get closer to the world of practice, they must tread carefully with regard to the consequences of their own work!

The final section of the SI features four extended papers. The first is offered by Gareth Edwards, Ken Parry, Michael Cohen, Sukanto Battacharya and Andrea North-Samardzic on the theme of belonging and community. It was one of the last pieces of work that Ken was engaged with and captures the methodological essence of Ken with regard to the use of mixed methods and aesthetic narrative analysis. A powerful finding from their empirical research suggests that if a follower rates "being part of the community" highly, then he/she is very likely to also report a "sense of belongingness towards the leader" (p. https://doi.org/10.1017/jmo.2019.28). Gareth and his colleagues argue that social identification derived from belongingness influences follower personal identification. The research has important implications for understanding charismatic leadership. Furthermore, the importance of belongingness and community speaks to aspects of leadership responsibility, purpose and place.

Connecting with notions of place, Emma Watton, Scott Lichtenstein and Paul Aitkin incorporate one of Ken's favourite songs into their title, 'Won't get fooled again'. The paper is based on the last keynote address that Ken gave in November 2015. In many ways it draws on the various threads that have been highlighted in the SI by exploring how personal values connect with core aspects of leadership such as purpose, behaviour and legacy. The paper offers us an opportunity to reflect on our own personal values and how our values impact on us in terms of 'Taking Our Lead'.

The penultimate article that is featured in this SI, written by Ralph Bathurst and Andrew Chrystall, would have been strongly supported by Ken to be included because it embraces so much that he stood for as a researcher, educator, editor and as a kindly provocateur to stimulate interest and exploration beyond the safe and trusted confines that dominate leadership research. The examination of Lee Child's best-selling book, Night School, and the leadership lessons drawn by its widely celebrated central protagonist, Jack Reacher, embrace an unexpected but ultimately joyous alternative perspective to appreciating leadership. Ken recognised that the humanities have much to offer the leadership field and the engaging and insightful interpretation of this text lingers long in reflective musings.

Fittingly, given Ken's passion for teaching, the final article that is presented in this SI focuses on the classroom, most especially the quest to create an authentic classroom in which leadership learning can genuinely thrive. Kevin Lowe highlights some of the key themes that emerged from a panel of leadership scholars that he organised for the 2018 International Leadership Association (ILA) conference theme, 'Authentic Leadership for Progress, Peace and Authority'. Drawing on the principles of authentic leadership the panel and the audience conversation centred on how the classroom experience would be different, for students and for lecturers, if everyone brought their full selves, their full engaged selves to the classroom and what the risks (i.e., pedagogic, career-building, legal and personal safety) might arise if we did this.

\section{Concluding Remarks ... 'But Here's The Thing!'}

The SI is not a celebration of Ken's life. That is not its purpose. Rather it is to offer up mostly short, and we hope fairly interesting and reasonably impactful contributions that might guide the future direction of leadership studies. As founding editor of the Journal of Management \& Organization, Ken expected articles to be well-written (with short sentences!), rigorous while avoiding rigour-mortis, and replete with plausible arguments. But more than all that, and we can hear his voice now saying: 'and the thing is?' What is the point of the research? What is 
its impact and relevance? There have been many debates about rigour and relevance - both are necessary but each alone is far from sufficient. Yet too often the relevance part of the partnership is sadly lacking.

The most fitting tribute to a great scholar would be that this SI provides some impetus to give much greater weight and voice to the relevance of leadership research. Leadership studies have for too long under-achieved in terms of its impact and some would argue, its rigour. If leadership is one of the most significant mechanisms for social influence, then it is vital that leadership research, development and teaching have far greater impact on leadership practice and responsibility in all fields of endeavour, not just within business. The grand challenges are gathering in a seemingly overwhelming cluster in the threatening manner of a perfect storm. Therefore, we need now more than ever leadership research that gives greater attention to furthering the place-based, purposeful leadership that can propel communities, organisations and networks to tackle and address these challenges.

Ken had a highly productive and long research life in which he shaped and reshaped the leadership field in so many ways. Ken was a fossicker, nurturer, propagator and promulgator of an extraordinary array of ideas and always at the forefront of the leadership field. He was and is a scholar of remarkable renown and this SI is a part of ensuring his legacy lives on.

As the Editorial Team mourned Ken's passing, and the Australian and New Zealand Academy of Management (ANZAM) Board was looking for a fitting way to honour him, the idea of a SI was born. Literally it took less than a week to get the Board and JMO's Editor to agree to honour Ken with his own SI. This was a first for ANZAM and JMO and Ken would have been delighted but equally curious about what all the fuss was about.

The Guest Editors naturally formed out of those who had been working with Ken very closely on research projects and were part of his inner circle of colleagues and friends and/or had connections with ANZAM and JMO. It is quite certain that we eventually included only a small subset of researchers who were close to Ken. We apologise again to those who would have wanted to be included in this SI. Our reviewers, all of whom knew Ken well, also did a fantastic job in enriching the contributions and meeting the tight deadlines associated with the SI. Literally everyone had to reschedule and reorganise their commitments, which they did gladly and generously for Ken.

We hope the SI does justice to Ken and his legacy. We are once again paying tribute to him as a giant in our field of leadership studies.

\section{References}

Boyle, M., \& Parry, K. W. (2007). Telling the whole story: The case for organizational autoethnography. Culture and Organization Journal, 13(3), 185-189.

Jackson, B., \& Parry, K. (2008). A very short, fairly interesting and quite cheap book about studying leadership (1st ed.). London: Sage.

Jackson, B., \& Parry, K. (2018). A very short, fairly interesting and quite cheap book about studying leadership (3rd ed.). London: Sage.

Kempster, S., \& Parry, K. (2018a). Beyond one voice: Co-constructed analytic auto-ethnography. In A. Bryman \& D. A. Buchanan (Eds.), Unconventional methodology in organization and management research (Chapter 9, pp. 168-189). Oxford: Oxford University Press.

Kempster, S., \& Parry, K. W. (2011). Grounded theory and leadership research: A critical realist perspective. Leadership Quarterly, 22(1), 106-120.

Kempster, S., \& Parry, K. W. (2018b). After leaders. In B. Carroll, J. Firth \& S. Wilson (Eds.), After leadership (Chapter 5, pp. 64-80). New York: Routledge.

Kempster, S., Maak, T., \& Parry, K. W. (2019). Good dividends: Responsible leadership of business purpose. Abingdon: Routledge.

MacIntyre, A. (1985). After virtue: A study in moral theory. London: Duckworth.

Parry, K. W. (1998). Grounded theory and social processes: A new direction for leadership research. Leadership Quarterly, 9 (1), 85-105.

Parry, K. W., \& Hansen, H. (2007). The organizational story as leadership. Leadership, 3(3), 281-300. 
Parry, K.W., \& Kempster, S. (2014). Love and leadership: Constructing follower narrative identities of charismatic leadership. Management Learning 45(1), 21-38.

Shamir, B., \& Kark, R. (2004). A single-item graphic scale for the measurement of organizational identification. Journal of Occupational \& Organizational Psychology, 77(1), 115-123.

\section{Editors' Reflections on Ken Parry}

The Special Issue is in honour of our esteemed colleague and friend, Professor Ken Parry. Each of the Editors had their own reasons for doing this for Ken. For Brad because Ken, in addition to being a great mate, introduced and opened up the field of leadership studies to him in the first place as well as the joys of Brisbane, Burleigh Heads and Australian Football; interventions he is eternally grateful for. For Steve as Ken was a very dear friend with whom he taught together, researched together, laughed enormously together and shared a passion for German beer which was often consumed together. For Liz, being a long-standing member of ANZAM and a colleague of Ken's at Griffith University, was instrumental in his taking on the Foundation Editorship of JMO and is ever so grateful he did. Ken's leadership of JMO was exemplary and pivotal to where the journal is today. It is so befitting that Ken's is the first dedicated SI JMO has chosen to publish.

Ken had an amazingly productive academic life and was internationally recognised and admired as a leadership scholar. He focused all his energy, wit, humour, passion and intellectual talents on teaching, researching and supervising PhDs. In all he did, Ken strove to take the lead, never accepting anything on face value or as it is, regularly opening a 'can of worms' in the leadership field, deftly throwing his fair share of 'stink bombs' at the establishment and, ingeniously finding the space, place and time to engage in his kind of scholarship. In fact, reflecting on Ken's academic life, he really was the perfect 'tempered radical' - one of those 'people who want to exist in their organizations yet want to live by their values and identities, even if they are at odds with the dominant culture of their organizations' (Meyerson, 2003, p. xi). Being such a person was a big part of his appeal, his creativity and his ability to push academic boundaries.

Ken's legacy in the field of leadership is immeasurable and irreplaceable. He has left us to ponder leadership from many rich and diverse perspectives, paradigms and angles and thus, forever forcing revisions, rethinks, rewrites and of course, rejections of popularly held ideas about leadership. He has left behind a great wealth of leadership theories and ideas that will remain a work-in-progress for us to debate, absorb, interpret, reinterpret, rework and make sense of for a lifetime to come. Reading one of Ken's pieces will almost always shake your confidence about leadership, be a wake-up call or a call to arms to think and act differently as leadership scholars and practitioners. But within these pieces, Ken invariably leaves you with some new and exciting treasure trove of leadership ideas. When, as Ken did, you enrich the lives of so many through your scholarship, you inspire in the most unimaginable and enduring ways. Ken, your followership is alive and thriving!

Meyerson, D. E. (2003). Tempered radicals: How everyday leaders inspire change at work. Boston, Massachusetts: Harvard Business School Press.

Cite this article: (2019). Professor Ken Parry Biography. Journal of Management \& Organization 25, 355-363. https:// doi.org/10.1017/jmo.2019.38 